\title{
Enhancing postgraduate researcher wellbeing through support groups
}

Fryni Panayidou

Queen Mary Academy, Queen Mary University of London

Benjamin Priest

Advice and Counselling Service, Queen Mary University of London

\section{Published in Studies in Graduate and Postdoctoral Education}

DOI: 10.1108/SGPE-06-2020-0038

\author{
Please cite as: \\ Panayidou, F. and Priest, B. (2021), "Enhancing postgraduate researcher wellbeing through \\ support groups", Studies in Graduate and Postdoctoral Education, Vol. ahead-of-print No. \\ ahead-of-print. https://doi.org/10.1108/SGPE-06-2020-0038
}

\section{Deposit License}

This author-accepted manuscript is deposited under a Creative Commons Attribution Noncommercial 4.0 International (CC BY-NC) licence. This means that anyone may distribute, adapt, and build upon the work for non-commercial purposes, subject to full attribution. If you wish to use this manuscript for commercial purposes, please contact permissions@emerald.com.

\section{Corresponding author}

Fryni Panayidou, f.panayidou@qmul.ac.uk

\section{Acknowledgements}

The Support Group was launched as part of the project "Supporting PGR mental health and well-being" at Queen Mary University of London, which was co-funded by the Office for Students and Research England Catalyst Fund: Supporting mental health and well-being for postgraduate research students. The project involved several teams working together, but we would like to particularly thank Magda Chanopoulou, Kevin Halon, Jessica Mayer Johnson, Anna Price and Laura SeQueira, for securing funding and/or discussions around the group process.

The Warwick-Edinburgh Mental Well-being Scale was funded by the Scottish Government National Programme for Improving Mental Health and Well-being, commissioned by NHS Health Scotland, developed by the University of Warwick and the University of Edinburgh, and is jointly owned by NHS Health Scotland, the University of Warwick and the University of Edinburgh. 


\begin{abstract}
Purpose This paper examines the effectiveness of $\mathrm{PhD}$ support groups as an intervention that improves mental wellbeing and increases confidence in timely PhD completion.

Design/methodology/approach Participants of six PhD support groups, which we cofacilitated, completed a survey at the start of the intervention and at the end of the eight weeks of attendance. The survey measured subjective wellbeing and confidence in completion using the Warwick-Edinburgh Mental Well-being Scale and statements from the Postgraduate Research Experience Survey (2017 and 2019). The final survey also included open-ended questions to identify the helpful factors of the intervention.

Findings Participants' subjective wellbeing scores increased considerably over the eight weeks of group attendance and improved from initial score ranges associated with risk of depression or psychological distress. As a result of feeling understood and supported by other group members, participants felt less isolated and anxious, were more satisfied with their life and work-life balance, and felt more confident about completing their $\mathrm{PhD}$ within the institutional timeframe. Our results confirm previous findings on the positive effects of social support and the relationship between poor wellbeing and attrition.
\end{abstract}

Originality Existing literature mainly highlights factors that affect postgraduate researchers' wellbeing, with limited research on innovative interventions. This paper investigates the impact of social support in a facilitated peer group that focuses on the emotional and psychological aspects of the $\mathrm{PhD}$ experience, rather than peer group learning or support with specific research tasks.

Practical implications Support groups could form an integral part of university support as they increase wellbeing and could improve retention. 


\section{Introduction}

Over the last decade, a growing literature has highlighted the prevalence of mental health issues and poor wellbeing in the postgraduate research student (PGR) population (e.g. Stubb et al., 2011; Levecque et al., 2017). PGRs face unique challenges which may impede mental health and wellbeing, such as difficulties in the supervisory relationship, financial worries, feelings of inadequacy and isolation (Metcalfe et al., 2018). Existing literature on PGR wellbeing mainly highlights risk factors, with limited research on innovative interventions that enhance PGR wellbeing, improve the overall PhD experience, and which may be integrated into existing university support systems.

This paper aims to address this gap by describing the practice and outcomes of PhD support groups at our institution. The groups were introduced as part of an 18-month funded project that aimed to support PGR mental wellbeing at our institution with new initiatives, such as wellbeing training for staff and PGRs. The support groups aimed to decrease isolation and improve mental wellbeing by providing a safe, confidential space in which participants could discuss and support each other with difficult issues related to the doctoral experience and their emotional or psychological impact.

We present quantitative and qualitative data from six support groups that we co-facilitated over two years. Our results confirm that social support is critical during the PhD journey and testify to the effectiveness of support groups in improving well-being, confidence in completion and the overall doctoral experience.

\section{Theoretical framework}

\section{Definitions}

There have been various attempts to address the problematic nature of 'wellbeing' as a concept and provide working definitions (e.g. McNaught, 2011; Dodge et al., 2012). Researchers acknowledge the difficulty of combining both subjective and objective definitions of wellbeing with cross-cultural relevance and application (e.g. Diener, 2009; La Placa et al., 2013). Our work was informed by Juniper et al. (2012), who focus their working definition of 'wellbeing' exclusively on those aspects that are influenced by the PhD role and university-based interventions. They introduce a wellbeing scale to investigate researchers' subjective perceptions and only use variables measuring aspects of wellbeing that an institution can influence. In line with Juniper et al. (2012), our approach used existing, widely used measures which capture the overall $\mathrm{PhD}$ experience and describe subjective wellbeing.

For our definition of 'support group' we adopt Kurtz's (1997) definition, as it captures the purposes and format of our groups:

Support groups meet for the purpose of giving emotional support and information to persons with a common problem. They are often facilitated by professionals and linked to a social agency or a larger, formal organization. Behavioral and societal change are subordinate to the goals of emotional support and education. Meetings are relatively unstructured, and the group's program is unlikely to espouse an ideology. (pp. 4-5) 
Levecque et al. (2017) found that PGRs are more than twice as likely to have or develop a common psychiatric disorder than the highly educated in the general population. Some of the factors that often lead to poor mental health in this population are issues within the supervisory relationship (Pyhältö et al., 2012), feelings of isolation (Ali and Kohun, 2006), dissatisfaction with the learning environment (Pyhältö et al. 2009), work-life balance and feelings of self-doubt (Juniper et al. 2012). These studies were based in Belgium, Finland, the United States and the United Kingdom, indicating that similar wellbeing issues are prevalent independent of the country or exact structure of the doctoral degree.

A critical implication of poor mental wellbeing in PGRs is that it can lead to attrition, with PGRs experiencing high levels of emotional exhaustion, stress, anxiety and isolation being more likely to withdraw from their programme (Ali and Kohun, 2006; Pyhältö et al., 2012; Hunter and Devine, 2016). In contrast, PGRs who feel supported within their learning environment are more engaged with their studies (Jairam and Kahl, 2012), exhibit significantly lower emotional exhaustion and are likely to successfully complete (Hunter and Devine, 2016). These PGRs are often in high-quality supervisory relationships and receive high levels of support from their departments.

These findings support the vast literature on the effect of social support on reducing stress and improving overall mental wellbeing (e.g. Viswesvaran et al., 1999; Halbesleben, 2006; Lakey and Orehek, 2011). Jairam and Kahl (2012) concluded that PGRs' social support networks, categorised into peers, supervisors and family, buffer stress levels and possibly increase retention. PGR participants in Jairam and Kahl's study indicated that they received emotional support from all three groups of individuals in their network, but highlighted the empathy, shared experience, and encouragement they received from their peers.

In order to prevent isolation and increase social support, Ali and Kohun (2006) recommend the formation of groups for PGRs. Some successful examples include a learning cohort that discussed dissertation-related issues (Burnett, 1999), an informal support group of four women during their dissertation phase (Denman et al., 2018), peer-to-peer mentoring (Bowman et al., 1990), and a peer-learning group that focused on research-related activities (Stracke, 2010).

While previous studies on PhD groups as social support interventions have focused on peer group learning or specific research tasks, our study is unique in that it describes a group that focuses on the emotional and psychological issues of doing a $\mathrm{PhD}$ and aims to improve both mental wellbeing and the overall doctoral experience.

\section{Support Groups}

Support groups do not usually embody a particular theoretical approach and research has focused on practice and evaluation of their effectiveness (Kurtz, 1997). While some of the features of support groups (e.g. confidentiality) overlap with therapy groups and peer groups, Schopler and Galinsky (1993) conceptualise these as a continuum. At one end, therapy groups focus on personality change through self-analysis and awareness, with the facilitator 
focusing on interpretation. At the other end, peer groups focus on a shared issue, without a formal leader and no single member taking responsibility for group conditions to be conducive to positive change (Rosenberg, 1984).

Support groups lie in the middle, in that they aim to increase the ability of participants to cope with the central issue - in our case, difficult emotions linked to the PhD experience - by focusing on group cohesion and enhancing self-esteem. The support group facilitators adopt a conscious, formal role as guardians of group boundaries, inclusivity, supportive discussion and promoters of a safe, open environment (Rosenberg, 1984).

Literature on effective group practice identifies several helping characteristics of peer, support and therapy groups (Rosenberg, 1984; Yalom, 1995; Schiff and Bargal, 2000). Given the aims of our intervention, we identified the following four characteristics as potentially useful to anyone attending a PhD support group:

a) Universality and an alternative to loneliness: the realisation that others have similar feelings regarding the shared situation, leading to a reduction in feelings of isolation;

b) Support: empathy, listening to others, and personal disclosure;

c) Communicating experiential knowledge: learning from own or others' experiences;

d) Instillation of hope: feeling inspired by observing improvement of others or a belief that the intervention may help participants.

The negative effects of support groups have received less attention (Schopler and Galinsky, 1993), but these may include: conformity, stress related to group obligations, feeling overwhelmed and inadequate, learning inappropriate responses, embarrassment, and overconfidence (Shumaker and Brownell, 1984). Communicating openly in a group setting can also feel intimidating and stressful for some (Richman, 1990). Regarding the group process, issues include irregular attendance or dropouts and dominating or disruptive participants. The conclusion of a group can also present a challenge to participants, even within the context of a relatively short support group intervention (Drebing, 2016). We discuss how we prevented or overcame some of these challenges in the next section.

While there are no previous studies on the effectiveness of $\mathrm{PhD}$ support groups as mental wellbeing interventions, previous research on support groups for people suffering with mental illness or for their caregivers suggests that they are effective in improving mental wellbeing across a broad range of focal issues and in various settings (e.g. Chou et al., 2002; Mancini et al., 2013; Worrall et al., 2018). Given the literature on the effectiveness of support groups and the increasing prevalence of common psychiatric disorders, such as anxiety and depression amongst the PGR population (Levecque et al. 2017), it seemed apt to introduce such an intervention at our institution.

\section{Methods}

\section{Support Group structure and participants}

Six support groups ran over two years, with three groups each year. Following a format of closed groups (Yalom, 1995), each group met weekly for 90 minutes over eight weeks with consistent membership. The groups were held face-to-face in a private counselling room on 
the main university campus, with chairs arranged in a circle so that all participants could see each other and read nametags. While the maximum recommended size of an interactional group is ten participants (Yalom, 1995), we recruited up to twelve participants in each group in the first year due to project pressures to reach as many PGRs as possible. In response to feedback and our observation that smaller groups shared more openly and connected more effectively, we reduced the recruitment number to ten in the second year. All groups were collaboratively facilitated by a Counsellor and a Researcher Developer (a university employee responsible for supporting the professional and personal development of PGRs through training, events and mentoring schemes).

The application to join a support group was open to PGRs across all disciplines and years of study who believed they could benefit from peer support on emotional issues related to the $\mathrm{PhD}$. Applicants were invited to a 15-minute appointment with the facilitators to discuss confidentiality, what they hoped to get out of the group, their PhD progress and any mental health or emotional concerns. Following the appointment, all applicants who wished to join a group were invited to join one; applicants who could benefit from individual counselling were directed to the institution's counselling service and were invited to join a support group after the end of their counselling sessions.

A total of 56 PGRs participated across the six support groups, with $70 \%$ of participants being female. This is considerably higher than the proportion of female PhD students at the institution, which is $50 \%$. This gender disparity is consistent with findings that women are more likely to have a common mental health problem and receive treatment than men (McManus et al., 2016), thus suggesting women could also be more likely to seek emotional support. The distribution of our participants closely matched the distribution of PGRs across faculties in the institution. However, the composition of each individual group was random, as places were offered on a first come, first served basis due to the limited duration of the funded project. Each group, therefore, varied in membership in terms of disciplines, gender, concerns, and pre-existing mental health conditions.

To create a close-knit group, we asked any participant who missed the first session of their allocated group or who missed any other two sessions over the eight weeks, to join a later group. We also set ground rules around confidentiality, arriving promptly, turning off phones, and being respectful towards each other.

Rather than focusing on improving performance through tasks, we tried to encourage a focus on aspects of the PhD experience which felt painful, difficult or debilitating through open discussion. In line with the helping features of support groups outlined above, we encouraged participants to share and support each other by listening to and acknowledging each other's experience and emotions.

After the first group, we introduced a weekly check-in at the beginning of each session so that everyone, including quieter participants, spoke at some point every week and participants could pick up on issues mentioned during check-in. After the second group, we introduced brief paired discussion at the very first session of each group on reasons that brought participants to the group. Paired discussion was useful for easing participants into 
sharing with the larger group. Sometimes, participants focused solely on systemic issues rather than individual change. To tackle this, we introduced a question at the start of the group process: "What would you like to change about your PhD experience? - focusing on things you can actually change yourself".

The main role of the facilitators was to facilitate communication by ensuring that members felt supported when bringing up difficult issues and by preventing participants from dominating the discussion. During the first meeting of each group, the facilitators modelled group communication skills through active listening and questioning, while participants were still familiarising themselves with the open-discussion format. The Researcher Developer often gave guidance relating to expectations, university systems, sources of support, and skills development. The main focus of the initiative, however, was on the emotional, psychological and relational aspects of the $\mathrm{PhD}$ experience addressed by the Counsellor.

\section{Measures}

We ran a quantitative survey at the start of the first session of each group (start of the intervention) and repeated the same survey, with the addition of three open-ended questions, during the last fifteen minutes of the eighth and final session of each group (end of the intervention).

To measure changes in subjective wellbeing and psychological functioning, the survey used the Warwick Edinburgh Mental Wellbeing Scale (WEMWBS). WEMWBS was developed and validated by researchers from the universities of Warwick and Edinburgh, with funding from NHS Health Scotland, to measure mental wellbeing in adults, independent of the presence of mental illness (Taggart et al., 2015). Participants were asked to respond to the 14 WEMWBS statements in (1), based on what best described their experience in the past two weeks. Each statement is scored on a 1-5 Likert scale and the score is calculated by summing the scores of all 14 statements (minimum score: 14, maximum: 70 ).

1. WEMWBS statements

a. I've been feeling optimistic about the future

b. I've been feeling useful

c. I've been feeling relaxed

d. I've been feeling interested in other people

e. I've had energy to spare

f. I've been dealing with problems well

g. I've been thinking clearly

h. l've been feeling good about myself

i. I've been feeling close to other people

j. l've been feeling confident

k. I've been able to make up my own mind about things

I. l've been feeling loved

$m$. I've been interested in new things

n. I've been feeling cheerful 
We chose WEMWBS as it is suitable for measuring change after short interventions and has been used in the 2016 Health Survey for England, thus allowing us to compare our participants' scores to those of the general population. WEMWBS scores have also been compared to surveys that measure mental illness, such as the Centre for Epidemiological Studies Depression Scale and the Edinburgh Post Natal Depression Scale. The comparison with these surveys suggests that WEMWBS scores between 41 and 45 are indicative of high risk of psychological distress and increased risk of depression (Taggart et al., 2015). Individuals with a score of $\leq 40$ are linked to high risk of major depression.

In order to compare the results of our participants to those of the general PhD population, the survey included statements from the Postgraduate Research Experience Survey (PRES). PRES is a robustly tested annual survey developed by AdvanceHE to gather information about the experience of PGRs across UK institutions and provide national benchmarking [1]. The statements in (2), from PRES 2017, are ranked on a five-point Likert scale from 'definitely disagree' to 'definitely agree'. The percentage of 'agree' figures is calculated by the addition of 'definitely agree' and 'mostly agree' responses and dividing by the overall number of responses.

\section{PRES 2017 statements}

a. I am confident that I will complete my research degree programme within my institution's expected timescale ${ }^{1}$

b. There is someone I can talk to about my day-to-day problems

c. I am satisfied with my life nowadays

d. I am satisfied with my work-life balance

In order to capture any differences between the wellbeing scores of those who had considered dropping out and those who had not, we included the binary PRES question that asks whether participants have, for any reason, considered leaving or suspending their postgraduate course.

In the second year of the initiative, we added to our survey the new wellbeing questions from PRES 2019, listed in (3). The questions are ranked on a scale from 0-10, where 0 is 'not at all' and 10 'completely'. The proportion of figures indicating good wellbeing is calculated by adding the number of responses at 7 or higher and dividing by the overall number of responses.

\section{PRES 2019 statements}

a. Overall, I am satisfied with life nowadays

b. Overall, I felt happy yesterday

c. Overall, I feel things I do in my life are worthwhile

d. Overall, I did not feel much anxiety yesterday

The three open-ended questions in the final survey, completed at the end of the eight sessions of each group, asked participants: a) what they thought were the most useful

\footnotetext{
${ }^{1}$ The statement on confidence is completion stayed the same in PRES 2019.
} 
aspects of the group experience, $b$ ) what could be done to improve it in the future, and $c$ ) what changes the university can make to improve the $\mathrm{PhD}$ experience. The first and second questions were asked to help us interpret the quantitative results and improve our practice. The final question was a requirement of our funding, as the overall project aimed to identify common concerns among PGRs and drive institutional change.

The qualitative responses were analysed using thematic content analysis as we expected the emergent themes to relate to both the helping and negative aspects of support groups discussed above. We also expected that the themes raised in the final question would closely align with the PGR-specific challenges that have been extensively discussed in previous literature.

Participants often mentioned more than a single issue/aspect in their qualitative responses; therefore, each issue/aspect was coded as a distinct theme. The reported frequency of each theme is based on the percentage of participants who mentioned that theme in their response.

\section{Number of responses and data considerations}

All 56 participants across the six groups completed the survey at the start of the intervention, but only a subset of 44 completed the final survey. This was because four participants were unable to attend the final session for practical reasons (e.g. illness) and eight dropped out before the end of the intervention. Six left early in the process, before week four, and this was usually to do with a discrepancy between their expectations of the intervention compared with the reality of the process. Some, perhaps, expected a space where participants would share practical tips and strategies, whilst a few found the process of sharing in a group difficult and opted for individual counselling instead. The two participants who left late in the process did not contact us to give a reason, so we might speculate that this was linked to difficult feelings about the ending of the group. The final responses for WEMWBS were 43 as one of the participants skipped the relevant section when completing the survey.

To improve our data and produce like-for-like responses in the second year of the initiative, we asked participants to randomly pick a code name, which they had to write on both their initial and final survey. This method ensured anonymity and allowed us to compare individual responses while excluding the initial responses of anyone who did not complete the final survey. We present and compare both methods of data collection below.

\section{Results}

\section{Quantitative results}

The average WEMWBS score across all 56 participants who completed the initial survey was 40.1. Figure 1 shows that the mean WEMWBS score of each individual group started within the ranges associated with poor mental health. At the end of the eight sessions, the average score of all 43 participants who completed the final survey was 48.6 , moving above 
the "risky" ranges and reaching closer to the mean score of England's population at 49.9 (Health Survey for England, 2016).

Figure 1: Mean WEMWBS scores at the start and end of the intervention

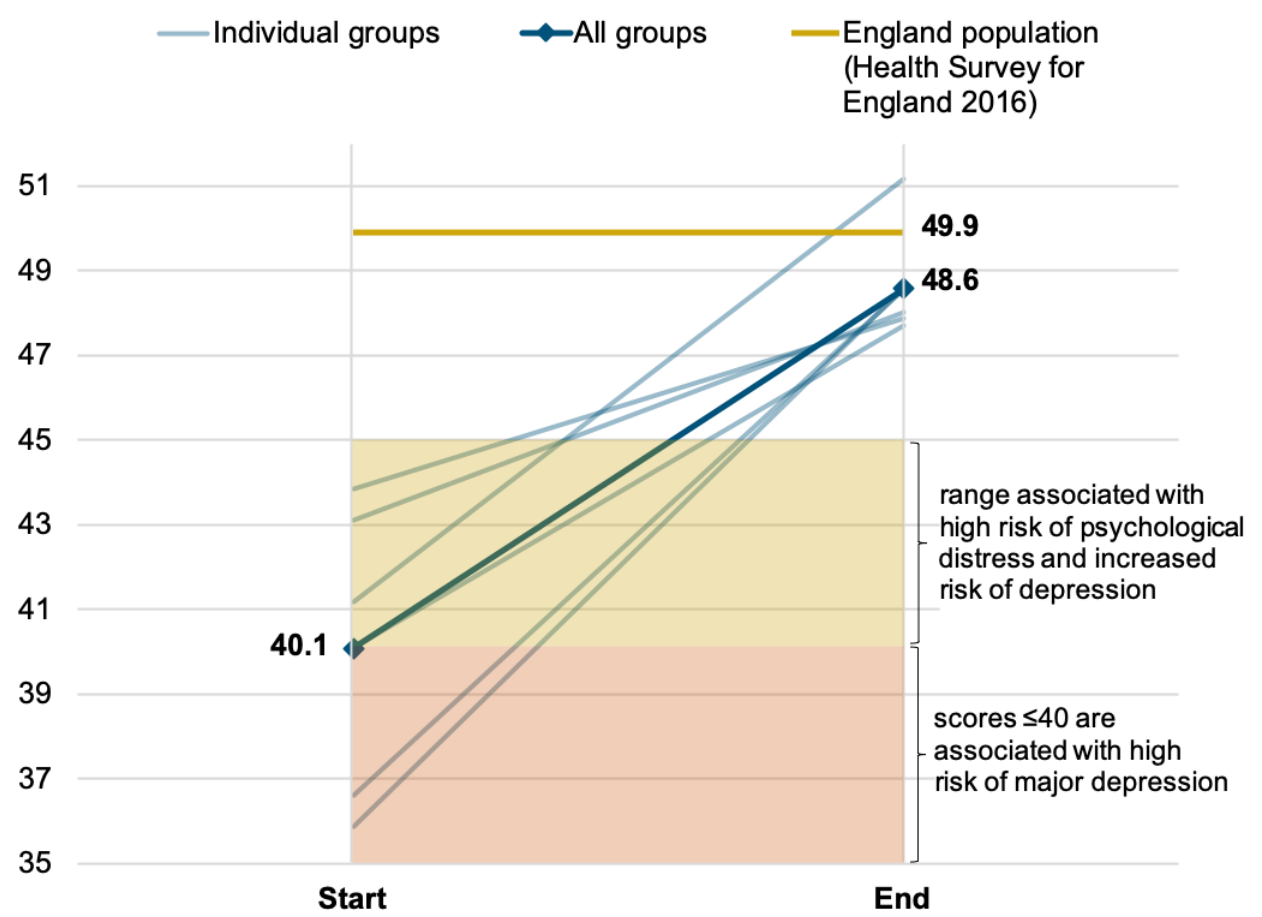

The distribution between the different ranges of scores shifted considerably between the start and end of the intervention (Fig.2). Most participants started with an individual score of $\leq 40$, which is associated with high risk of major depression. In the final responses, most participants' individual scores are 46 or higher, therefore moving above the 41-45 range that is associated with high risk of psychological distress and increased risk of depression. This pattern is observed both in the data across all participants and in the improved data, in which all 22 participants completed both the initial and final survey.

Figure 2: Distribution of individual WEMWBS scores at the start and end of the intervention

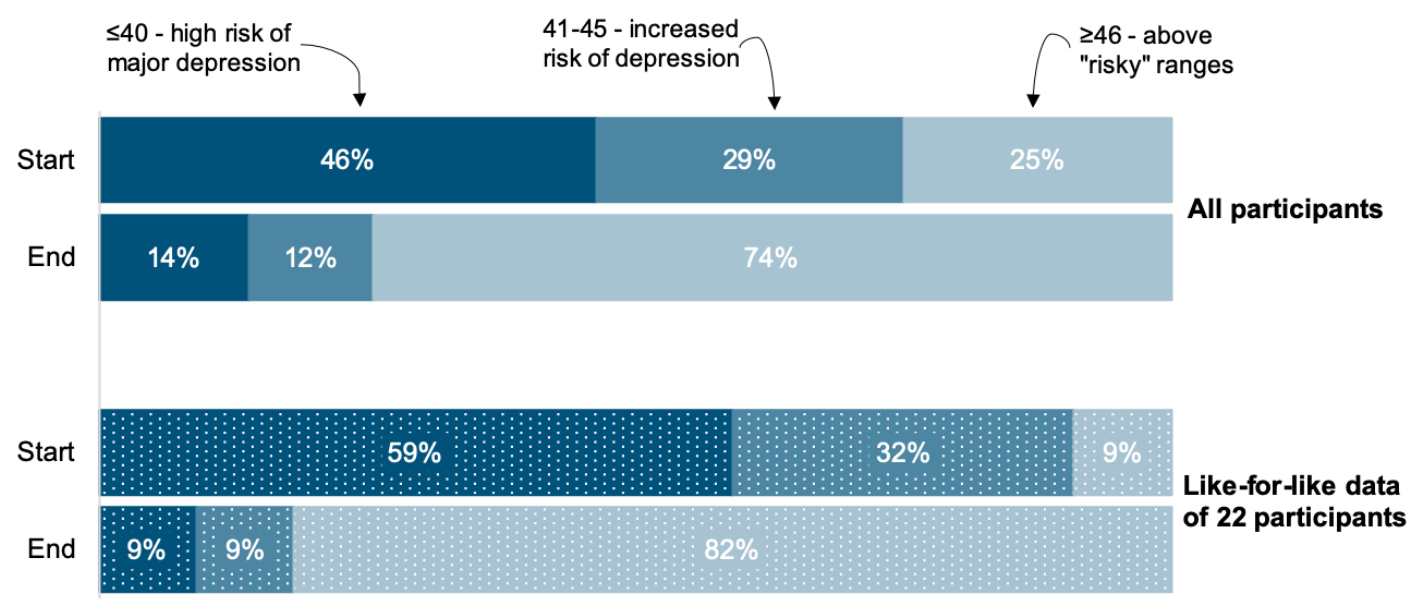


Participants who had stated in the initial survey that they had considered leaving or suspending their $\mathrm{PhD}$ programme, were also more likely to have a lower individual WEMWBS score at the start of the intervention than the rest (Fig.3).

Figure 3: Participants who had considered leaving or suspending their PhD studies were more likely to have a lower individual WEMWBS score at the start of the intervention

Have you considered, for any reason, leaving or suspending your postgraduate course?

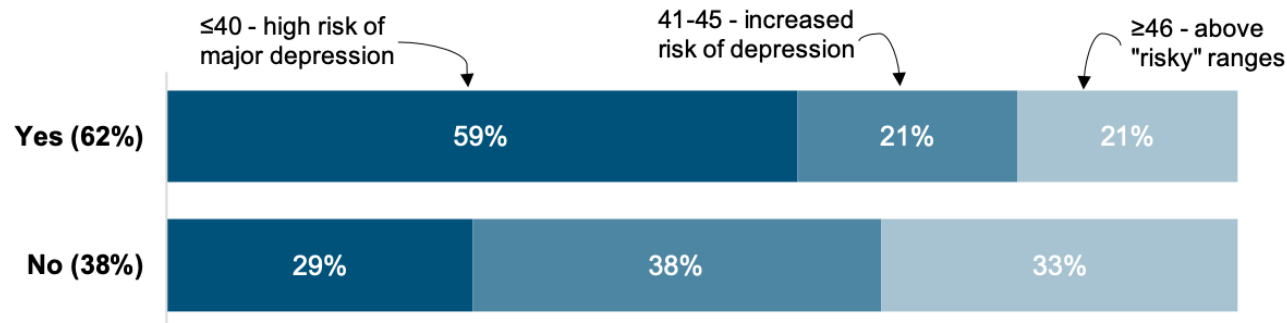

Participants' responses increased across all three PRES 2017 wellbeing statements, with a higher percentage of participants agreeing that they had someone to talk to about day-to-day problems compared to the $\mathrm{PhD}$ population (Fig.4). The pattern is similar in the improved, like-for-like data.

Figure 4: Responses to the PRES 2017 wellbeing questions at the start and end of the intervention

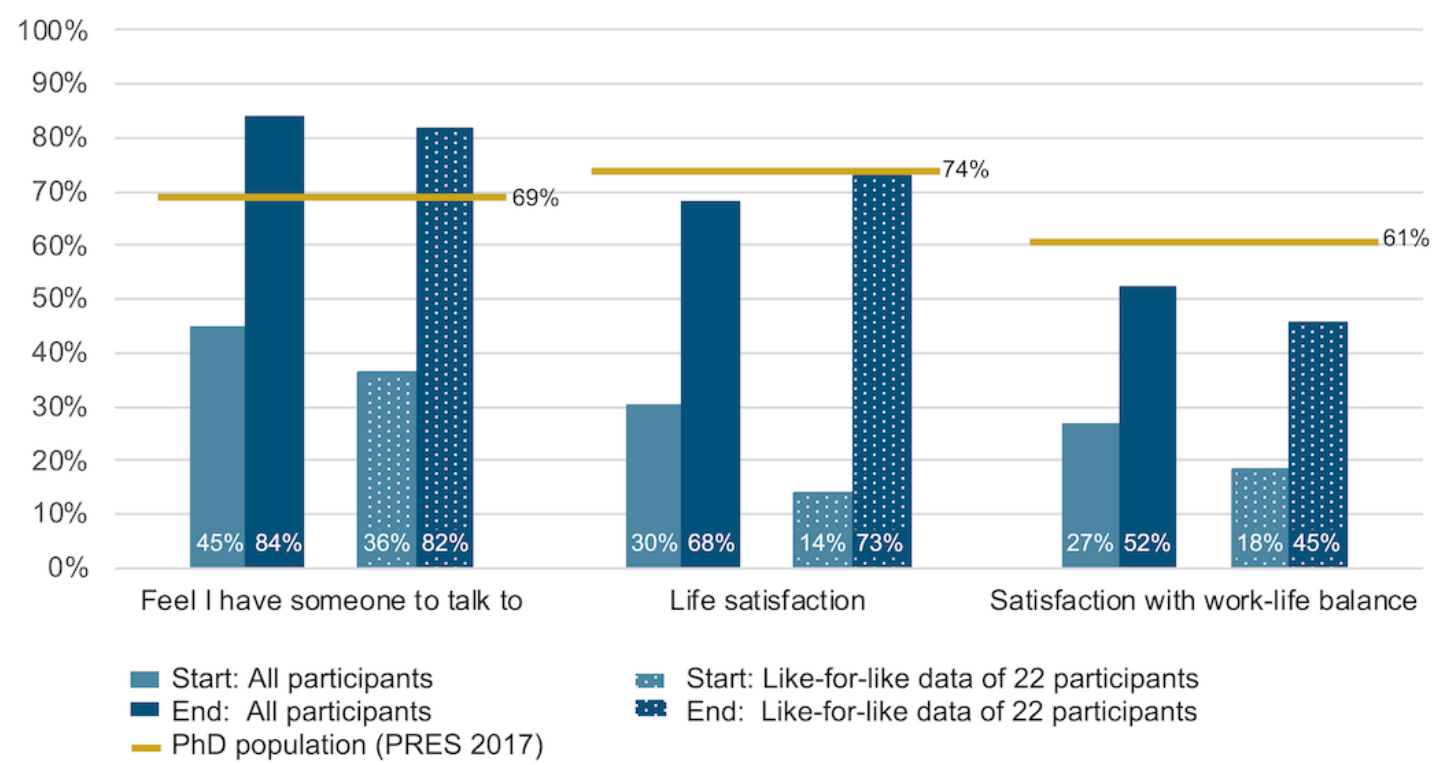

For the PRES 2019 wellbeing statements, which were added to the survey in the second year of the initiative, we looked at the like-for-like data in which the same 22 individuals completed the initial and final surveys. There was improvement in all four statements, with life satisfaction and low anxiety exceeding the scores of the PhD population (Fig.5). 
Figure 5: Responses to the PRES 2019 wellbeing questions at the start and end of the intervention

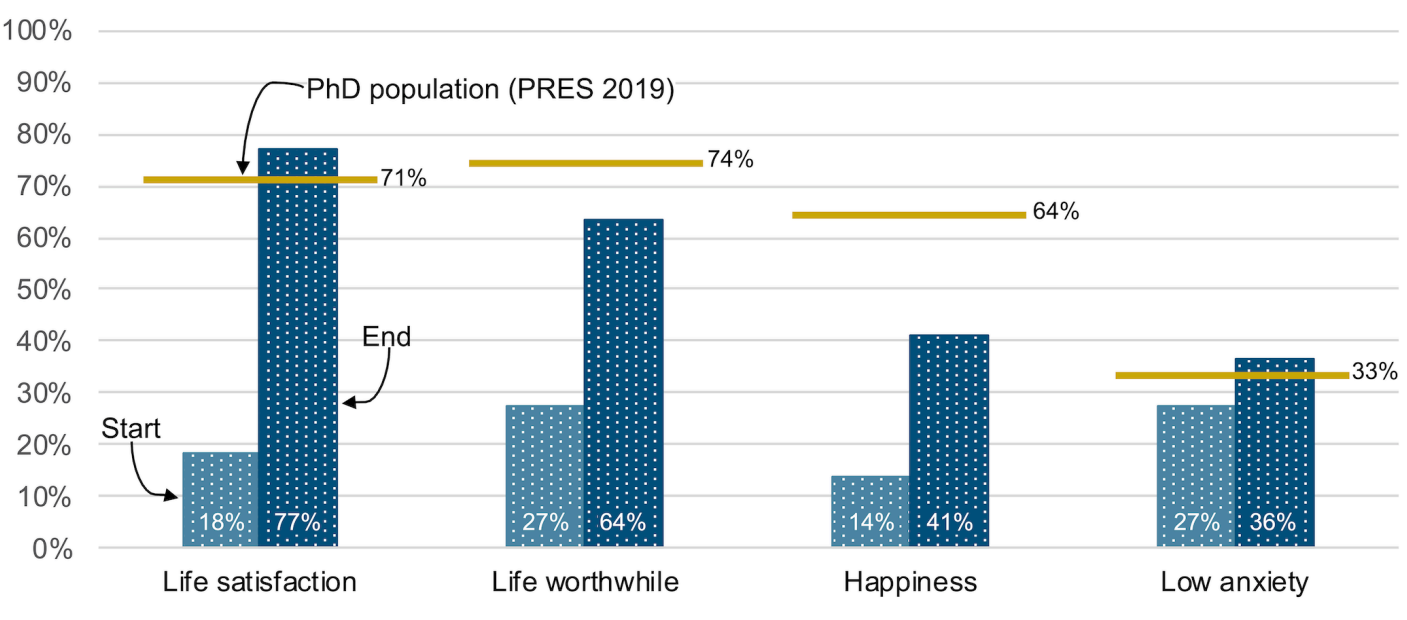

By the end of the intervention, participants also felt more confident that they would complete their PhD within the institution's expected timescale (Fig.6). The percentage of participants agreeing with this statement, across all participants and in the like-for-like data, exceeds that of the general PhD population, measured at 82\% in both PRES 2017 and 2019.

Figure 6: Confidence in timely completion at the start and end of the intervention

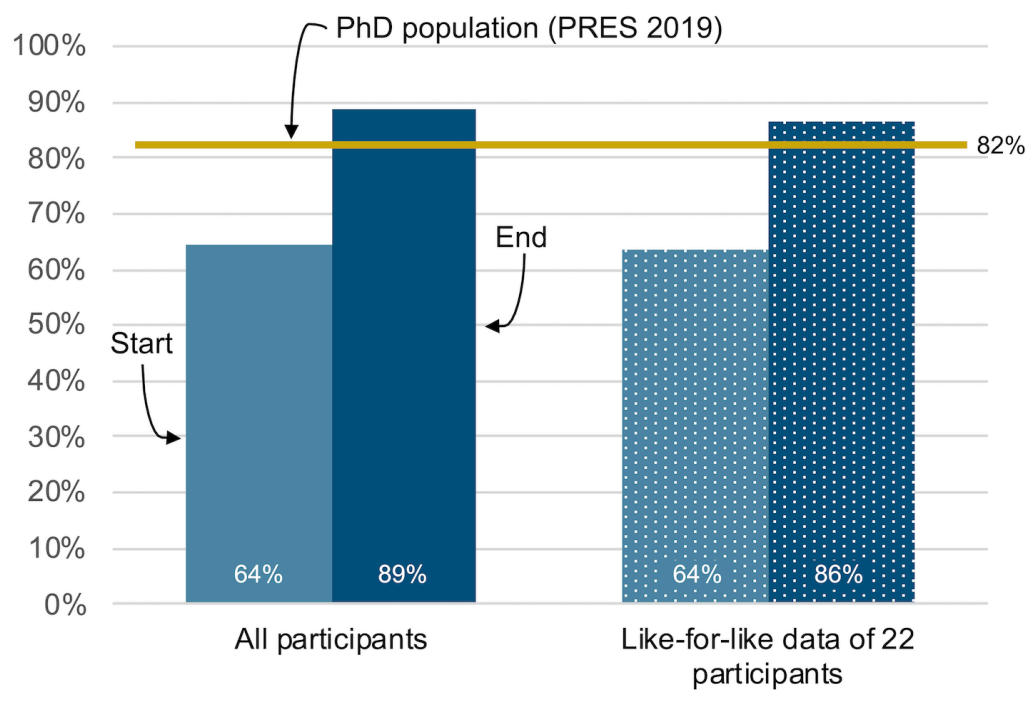

\section{Qualitative findings}

Table 1 presents the themes of the three open-ended questions asked at the end of the eight sessions with illustrative quotes. All useful aspects mentioned by participants are captured by the four helping characteristics of support groups mentioned in the theoretical framework. In terms of improvements to the group and institutional changes, the table only includes the most prominent themes that were identified by at least $20 \%$ of participants. 
Table 1: Thematic analysis of open-ended questions at the end of the intervention

\begin{tabular}{|c|c|}
\hline $\begin{array}{l}\text { Themes (response } \\
\text { frequency } \geq 20 \% \text { ) }\end{array}$ & Illustrative quotes \\
\hline \multicolumn{2}{|c|}{ 1. What were the most useful aspects of the support group experience? } \\
\hline $\begin{array}{l}\text { Universality \& } \\
\text { alternative to } \\
\text { loneliness } \\
(68 \%)\end{array}$ & $\begin{array}{l}\text { "It was so good to hear first-hand accounts from others in my position. Often I } \\
\text { would find myself recalling something someone said in the group and feeling } \\
\text { better that the same thoughts had crossed others' minds." } \\
\text { "It is an incredible experience with great impact both on a personal and } \\
\text { professional capacity. Having a group of people going through similar issues or } \\
\text { that have gone through them makes you feel less alone and you get great tips" }\end{array}$ \\
\hline $\begin{array}{l}\text { Support } \\
(68 \%)\end{array}$ & $\begin{array}{l}\text { "It was useful] to feel empathy \& compassion in the room" } \\
\text { "Talking about common PhD issues in a serious and kind environment - not only } \\
\text { in a joke-y way as is usually done between PhD students. Feeling like people } \\
\text { care about me." }\end{array}$ \\
\hline $\begin{array}{l}\text { Communicating } \\
\text { experiential } \\
\text { knowledge } \\
(52 \%)\end{array}$ & $\begin{array}{l}\text { "Others' experiences and insights of tackling future challenges." } \\
\text { "Hearing what other people were going through helped to give me a perspective } \\
\text { on my own issues." }\end{array}$ \\
\hline $\begin{array}{l}\text { Instilling hope } \\
(48 \%)\end{array}$ & $\begin{array}{l}\text { "Reassurance that everything is actually going okay, even when it feels like it } \\
\text { isn't." } \\
\text { "Receiving support from the group leaders and from the fellow PhD students has } \\
\text { given me courage and strength to tackle my } \mathrm{PhD} \text { and try to make it a good } \\
\text { experience for me - because the group has also helped me realise that my } \\
\text { difficulties in my PhD are not entirely my fault and that I deserve to be happy in } \\
\text { my PhD." }\end{array}$ \\
\hline \multicolumn{2}{|c|}{ 2. What do you think could be done to improve this group in the future? } \\
\hline $\begin{array}{l}\text { Longer duration } \\
(41 \%)\end{array}$ & $\begin{array}{l}\text { "I have very good overall opinion about the support group. So, the only thing I } \\
\text { can suggest is the extension of the period in which the meetings happen to the } \\
\text { entire academic year." }\end{array}$ \\
\hline $\begin{array}{l}\text { More structure } \\
(25 \%)\end{array}$ & $\begin{array}{l}\text { "I really liked the unstructured nature of letting people express themselves but } \\
\text { maybe more structure would allow the shyer people more time to express } \\
\text { themselves, and move on from repetitions" }\end{array}$ \\
\hline \multicolumn{2}{|c|}{ 3. What could the university change to improve the PhD experience? } \\
\hline $\begin{array}{l}\text { Supervisor training } \\
\text { and accountability } \\
(70 \%)\end{array}$ & $\begin{array}{l}\text { "More training for supervisors would actually help. Just because they might be } \\
\text { good academics it doesn't mean they are good managers/leaders. Perhaps } \\
\text { something like a 360-degree appraisal system would be beneficial to monitor } \\
\text { this." }\end{array}$ \\
\hline $\begin{array}{l}\text { Early guidance } \\
(30 \%)\end{array}$ & $\begin{array}{l}\text { "I think there must be some training for PhD students on managing expectations } \\
\text { - perhaps a buddy system where 1st and 3rd years are paired to help each } \\
\text { other with adjusting to the PhD in Year 1." }\end{array}$ \\
\hline $\begin{array}{l}\text { Mental wellbeing } \\
\text { support } \\
(27 \%)\end{array}$ & $\begin{array}{l}\text { "[The university] should promote mental health programmes to PhDs a lot more, } \\
\text { making them like a routine and not something too special, so it is easier for a } \\
\text { student to seek help." }\end{array}$ \\
\hline $\begin{array}{l}\text { Building } \\
\text { communities }(25 \%)\end{array}$ & $\begin{array}{l}\text { "Create a more 'community feel' for PhD students so that they can meet other } \\
\text { students e.g. [Doctoral Society]. Give PhD students: a) some space to socialise - } \\
\text { physical space and maybe a monthly, very simple event; b) a PhD forum to } \\
\text { create a space for people to share potential collaborations [and] share events for } \\
\text { students to engage with." }\end{array}$ \\
\hline $\begin{array}{l}\text { Research culture } \\
\text { (hierarchies, } \\
\text { workload, } \\
\text { casualisation) } \\
(20 \%)\end{array}$ & $\begin{array}{l}\text { "Part of this is about workload - casualisation and relying on PhDs to TA impacts } \\
\text { on time and morale. Acknowledge the systemic issues that contribute to mental } \\
\text { health - wellbeing is good but not enough. Support and fund groups like this so } \\
\text { more PhDs can benefit from group meetings. Stop the culture of overwork that } \\
\text { affects permanent staff and PhDs alike." }\end{array}$ \\
\hline
\end{tabular}


Additional themes for group improvements, each identified by $7 \%$ of participants, were: maintaining participant connection outside the group environment, inclusion of practical exercises such as mindfulness, and grouping participants by concern or year of study. Recommendations for institutional improvements included: more opportunities for PGRs to feed back to the institution, extending funding to include a write-up year, and access to better research facilities (each identified by $14 \%$ of participants). Less prominent themes were the provision of core research training $(7 \%)$ and writing support $(5 \%)$.

\section{Support during Covid-19}

The final three sessions of the final group running in the second year of the initiative coincided with the Covid-19 lockdown in the spring of 2020 and were consequently held online on MS Teams.

We expected the combination of the lockdown and change in mode of delivery to have negative effects on this group's results. However, the individual WEMWBS scores of all participants in this group increased by the end of the group, with the lowest individual increase at 3 points and the highest at 20 .

The responses of the six participants who completed both the initial and final survey and had consistently attended the group throughout the eight weeks, show that there was some improvement in most PRES statements, but satisfaction with work-life balance and happiness remained unchanged. Participants also felt more anxious at the end of the group than they did at the start. This is unsurprising given the disruption and uncertainty caused by the pandemic.

The open-ended comments in the final survey reflect participants' appreciation for carrying on with this support during the lockdown. One participant mentioned that it was "hard to imagine how things might have been 'without' the group; it felt like this may have been invaluable for just touching base regularly", while another participant mentioned that one of the best aspects about the group experience was that it continued during the coronavirus outbreak.

\section{Discussion}

The starting WEMWBS scores of participants were lower than we had expected, with $75 \%$ scoring within ranges associated with high or increased risk of depression and psychological distress. These low scores reflect self-selecting participants of a support group and, we can surmise, many were already experiencing significant wellbeing and mental health issues, which interfered with their ability to function as PhD students and affected their personal lives and relationships.

The final WEMWBS scores confirm that PhD support groups are effective mental wellbeing interventions; the intervention increased participants' subjective wellbeing, with the scores of $74 \%$ of participants moving above the "risky" ranges and the average score of all groups 
reaching close to that of England's general population. The PRES statements further confirm an increase in wellbeing, with participants feeling happier, more satisfied with their life and work-life-balance, and having lower anxiety levels.

Participants who had considered leaving or suspending their PhD programme prior to joining a support group were more likely than other participants to start with individual WEMWBS scores within the "risky" ranges. This is in line with literature on the relationship between PGR wellbeing and attrition (Ali and Kohun, 2006; Pyhältö et al., 2012). The share of participants expressing confidence in completing their $\mathrm{PhD}$ within the expected timeframe increased by 25 percentage points by the end of the intervention, supporting previous findings that access to support and good mental wellbeing are critical to successful completion (Hunter and Devine, 2016; Peltonen et al., 2017).

In addition to PhD support groups being effective mental wellbeing interventions, the results confirm that they are effective mechanisms of social support. To proportion of participants agreeing that they had someone to talk to at the end of the intervention was considerably higher compared to the PhD population. These results suggest that social support is not only provided by a PGR's departmental peers and supervisor (Jairam and Kahl, 2012), but can also be found in formal institutional support.

The qualitative results help us identify the characteristics of the intervention that made the greatest impact in improving participants' wellbeing and $\mathrm{PhD}$ experience. The majority of participants identified 'universality' (Yalom, 1995) as one of the most useful aspects of the intervention. The experience of being in a group where others share similar problems leads to a sense of connection and relief, and helps members feel less alone (Schiff and Bargal, 2000). This helping characteristic was fundamental in informing our thinking when setting up this initiative, as feelings of isolation and a lack of sense of belonging have been identified as possible detriments to PGR mental health (Metcalfe et al., 2018). Jairam and Kahl's (2012) participants, who identified their peers as the most prominent source of social support, also emphasised the helpfulness of the commonality in concerns.

The remaining helpful characteristics of feeling supported, learning through experience and instillation of hope also align with existing literature on social support and therapeutic factors of effective groups. Participants commented that the presence of the facilitators increased the sense that support can be found at the university, thus further instilling hope in them. In general, the intervention enabled participants to see that shared environmental or structural issues, rather than individual short-comings or inadequacies, may be significant factors in stress, depressive mood and anxiety.

The suggestions for improving the group in the future mainly related to an increase in the duration of the support group beyond the eight sessions. Given the resourcing constraints, we were not able to make this change, nor were we able to group participants by concern or year of study. Participants in earlier groups, asked for more structure during the sessions in order to make it easier for quieter participants to share; in response we introduced the weekly check-in and paired discussion during the first sessions discussed in Methods. 


\section{Limitations of the study}

The introduction of the PhD Support Group was conceived as a practical intervention rather than as a research project. We invited all who expressed an interest to meet with us and we did not recruit participants with the aim of constructing an ideal research sample.

Consequentially, the self-selecting sample is not necessarily representative of any broader population.

While the six groups' composition varied in terms of disciplines, gender, concerns and preexisting mental health conditions, results are surprisingly similar across all groups. The mean WEMWBS scores of each group varied significantly at the start of the eight sessions, yet five out of six groups ended with mean scores close to the score of the general population, between 47.7 and 48.6 (Fig.1). The sixth group had a final mean score of 51.2, but this higher score could be attributed to one participant's individual score, which improved by 20 points by the end of the group. With this participant's responses excluded from the sample, the final mean score of the sixth group decreases to 47.8 , thus following the pattern observed across all other groups. The results of the PRES statements are also similar across the six groups.

Another shortcoming of our data is that we have not yet investigated whether the positive effects of attending a support group are long-lasting. Qualitative feedback suggests that participants would have liked for this support to continue over a longer period, for example, throughout a year, or to regroup every few months to check in with others. These are options that we have not yet explored and could make a greater impact to participants' $\mathrm{PhD}$ experience and wellbeing.

\section{Practical recommendations}

The similarity in the results at the end of each group suggests that support groups are effective interventions regardless of individual participant characteristics and could be adopted by any university with similar results. Our groups helped PGRs feel emotionally supported and less anxious, improved their satisfaction with their life and work-life balance, and built their confidence in completing their $\mathrm{PhD}$ in a timely manner. Universities that introduce support groups with a similar format to ours should expect an overall improvement in participants' wellbeing and, therefore, greater engagement of participants with their studies.

When considering adaptation of this model to other universities there are four key elements to consider. The first of these is confidentiality; in our case, participants and facilitators had to agree to the confidentiality guidelines of the institution's counselling service to ensure a safe environment. The second key element concerns the distance of the facilitators in relation to the participants; neither of the facilitators were situated within the participants' departments, allowing for sharing without fear of a conflict of interest. The third element is the combined expertise of facilitators in counselling/therapy and thorough understanding of the doctoral experience. The final element is confidential supervision for facilitators; regular supervision by an experienced group practitioner is invaluable, as this work can be emotionally demanding and, at times, very challenging. 
The main challenge for adopting this initiative will be resourcing; running three to four groups in a year demands 0.1 FTE for each of the facilitators' time, including time spent to promote, recruit, and evaluate each group. Evaluation is important as, in our case, the strong outcomes of the intervention helped us secure further funding beyond the initial 18-month funded period. If funding is available, we recommend extending the duration of each group beyond eight weeks, as suggested by several of our participants. We would also recommend allowing more time for the administration of the process, including the individual appointments with potential participants, as this can be very time-consuming.

The qualitative data on what changes the university can make to improve the PhD experience reflect common issues that pose risks to mental wellbeing and can be used as recommendations for any university. Supervisory concerns are the most common with participants suggesting mandatory supervisor training on management skills and mental health awareness. They also recommend incentivising supervisors to improve their practice, through peer review or recognition (e.g. the UKCGE's Research Supervision Recognition Programme [2]). The second most popular suggestion was guidance of expectations and available support systems at an early stage of the $\mathrm{PhD}$, or even prior to joining a programme. Universities are encouraged to reduce stigma through the introduction of preventative mental health initiatives, such as support groups and training for staff and students. Participants acknowledge the importance of social support and ask for more opportunities to connect with peers outside their immediate environment, for example, through doctoral societies. Finally, they call for a change in a research culture which currently rewards unhealthy behaviours such as competitiveness and overwork.

\section{Conclusion}

This paper showed that support groups, which focus on examining emotional and psychological issues related to the $\mathrm{PhD}$, are very effective in enhancing PGR wellbeing and improving the overall doctoral experience. The results show that subjective wellbeing scores of participants increased considerably over the eight weeks of attending a support group and improved from initial score ranges that are associated with risks of depression or psychological distress. After completing the support group, participants felt less isolated and anxious, were more satisfied with their life and work-life balance and felt much more confident that they could complete their $\mathrm{PhD}$ within the institutional timeframe. These improvements were the result of participants feeling supported by peers, who shared similar feelings and experiences related to the $\mathrm{PhD}$.

Institutions looking for innovative interventions to support their PGRs could integrate our model within their existing support systems and expect similar results. 


\section{Notes}

1. https://www.advance-he.ac.uk/reports-publications-and-resources/postgraduate-researchexperience-survey-pres (accessed 26 September 2020)

2. https://supervision.ukcge.ac.uk (accessed 27 September 2020)

\section{References}

Ali, A., and Kohun, F., (2006), "Dealing with isolation feelings at IS doctoral programs", International Journal of Doctoral Studies, Vol 1, pp. 21-33.

Bowman, R.L., Bowman, V.E. and DeLucia, J.L. (1990), "Mentoring in a graduate counseling program: Students helping students", Counselor Education and Supervision, Vol. 30 No. 1, pp.58-65. DOI: 10.1002/j.1556-6978.1990.tb01179.x

Burnett, P.C. (1999), "The Supervision of Doctoral Dissertations Using a Collaborative Cohort Model", Counselor Education and Supervision, Vol. 39, pp.46-52.

DORi:10.1002/j.1556-6978.1999.tb01789.x

Chou, K.R., Liu, S.Y. and Chu, H. (2002), "The effects of support groups on caregivers of patients with schizophrenia", International journal of nursing studies, Vol. 39 No.7, pp.713722.

Denman, P.M., Corrales, J.M., Smyth, S. and Craven, K. (2018) "From ABD to PhD: A Qualitative Study Examining the Benefits of a Support Group During Dissertation in an Online Doctoral Program", The Journal of Continuing Higher Education, Vol. 66 No.2, pp.106-114. DOI: 10.1080/07377363.2018.1469067

Diener, E. (2009). "Conclusion: the well-being science needed now", Diener, E. (Ed.), The science of wellbeing, Social Indicators Research Series, Vol 37. Springer, Dordrecht, pp.267-271. DOI: 10.1007/978-90-481-2350-6

Dodge, R., Daly, A.P., Huyton, J. and Sanders, L.D. (2012), "The challenge of defining wellbeing", International Journal of Wellbeing, Vol. 2 No.3, pp.222-235. DOI:

10.5502/ijw.v2i3.4

Drebing, C. (2016), Leading Peer Support and Self-Help Groups, Alderson Press, Holliston, MA.

Halbesleben, J.R.B. (2006), "Sources of social support and burnout: A meta-analytic test of the conservation of resources model", Journal of Applied Psychology, Vol. 91 No.5, pp.1134-1145. DOI: 10.1037/0021-9010.91.5.1134

Health and Social Care Information Centre (2017), Health Survey for England 2016: Wellbeing and mental health, NHS Digital, available at: https://digital.nhs.uk/data-andinformation/publications/statistical/health-survey-for-england/health-survey-for-england-2016 (accessed 26 June 2020).

Hunter, K.H. and Devine, K. (2016), "Doctoral students' emotional exhaustion and intentions to leave academia", International Journal of Doctoral Studies, Vol. 11, pp.35-61. DOI: $10.28945 / 3396$. 
Jairam, D. and Kahl Jr., D.H. (2012), "Navigating the doctoral experience: The role of social support in successful degree completion", International Journal of Doctoral Studies, Vol. 7, pp.311-329. DOI: 10.28945/1700

Juniper, B., Walsh, E., Richardson, A. and Morley, B. (2012), "A new approach to evaluating the well-being of $\mathrm{PhD}$ research students", Assessment \& Evaluation in Higher Education, Vol. 37 No. 5, pp.563-576. DOI: 10.1080/02602938.2011.555816.

Kurtz, L.F. (1997), Self-help and support groups: a handbook for practitioners, Sage Publications Inc., Thousand Oaks, CA.

La Placa, V., McNaught, A. and Knight, A. (2013), "Discourse on wellbeing in research and practice", International Journal of Wellbeing, Vol. 3 No. 1, pp.116-125. DOI: 10.5502/ijw.v3i1.7

Lakey B. and Orehek E. (2011), "Relational regulation theory: A new approach to explain the link between perceived social support and mental health", Psychological Review, Vol. 118 No. 3, pp.482-495. DOI: 10.1037/a0023477

Levecque, K., Anseel, F., De Beuckelaer, A., Van der Heyden, J. and Gisle, L. (2017), "Work Organisation and Mental Health Problems In PhD Students", Research Policy, Vol. 46 No. 4, pp.868-879. DOI: 10.1016/j.respol.2017.02.008.

Mancini, M.A., Linhorst, D.M., Menditto, A.A. and Coleman, J. (2013), "Statewide implementation of recovery support groups for people with serious mental illness: a multidimensional evaluation", The journal of behavioral health services \& research, Vol.40 No. 4, pp.391-403. DOI: 10.1007/s11414-013-9351-1

McManus, S., Bebbington, P., Jenkins. R. and Brugha T. (Eds.) (2016) Mental health and wellbeing in England: Adult Psychiatric Morbidity Survey 2014, NHS Digital, Leeds, available at: http://content.digital.nhs.uk/catalogue/PUB21748/apms-2014-full-rpt.pdf (accessed 26 September 2020).

McNaught, A., (2011), "Defining wellbeing", Knight, A. and McNaught, A. (Eds.). Understanding wellbeing: An introduction for students and practitioners of health and social care, Lantern Publishing, Banbury, pp.7-23.

Metcalfe, J., Wilson, S. and Levecque, K. (2018) Exploring wellbeing and mental health and associated support services for postgraduate researchers, Vitae, available at: https://re.ukri.org/documents/2018/mental-health-report/ (accessed 29 June 2020).

Peltonen, J., Vekkaila, J., Rautio, P., Haverinen, K. and Pyhältö, K. (2017). “Doctoral students' social sup- port profiles and their relationship to burnout, drop-out intentions, and time to candidacy". International Journal of Doctoral Studies, Vol. 12, pp.157-173.

Pyhältö, K., Stubb J. and Lonka, K. (2009), “Developing scholarly communities as learning environments for doctoral students", International Journal of Educational Development, Vol. 14, pp.221-32. DOI: 10.1080/13601440903106551.

Pyhältö, K., Toom, A., Stubb, J. and Lonka, K. (2012), "Challenges of Becoming a Scholar: A Study of Doctoral Students' Problems and Well-Being", ISRN Education Vol. 2012. pp.1-12. DOI: $10.5402 / 2012 / 934941$

Richman, J.M. (1990), "Groupwork in a hospice setting", Social Work with Groups, Vol. 12 No.4, pp.171-184. DOI: 10.1300/J009v12n04_11 
Rosenberg, P.P. (1984), "Support Groups: a special therapeutic entity", Small Group Behavior, Vol. 15 No. 2, pp.173-186. DOI: 10.1177/104649648401500202

Schiff, M. and Bargal, D. (2000), "Helping Characteristics of Self-Help and Support Groups: Their Contribution to Participants' Subjective Well-Being", Small Group Research, Vol. 31 No. 3, pp.275-304. DOI: 10.1177/104649640003100302.

Schopler, J.H. and Galinsky, M.J. (1993) "Support Groups as Open Systems: A Model for Practice and Research", Health \& Social Work, Vol. 18 No. 3, pp.195-207.

Shumaker, S.A. and Brownell, A. (1984) "Toward a Theory of Social Support: Closing Conceptual Gaps", Journal of Social Issues, Vol. 40 No. 4, pp.11-36. DOI: 10.1111/j.15404560.1984.tb01105.x

Stracke, E. (2010), "Undertaking the Journey Together: Peer Learning for a Successful and Enjoyable PhD Experience", Journal of University Teaching \& Learning Practice, Vol. 7 Number 1, pp.1-12.

Stubb, J., Pyhältö, K. and Lonka, K. (2011), "Balancing between inspiration and exhaustion: PhD students' experienced socio-psychological well-being”, Studies in Continuing Education, Vol. 33 No. 1, pp.33-50. DOI: 10.1080/0158037X.2010.515572

Taggart, F., Stewart-Brown, S. and Parkinson, J. (2015), Warwick-Edinburgh Mental Wellbeing Scale (WEMWBS): User guide - Version 2, NHS Health Scotland.

Viswesvaran, C., Sanchez J.I. and Fisher, J. (1999) "The Role of Social Support in the Process of Work Stress: A Meta-Analysis", Journal of Vocational Behavior, Vol. 54 No 2, pp.314-334. DOI: 10.1006/jvbe.1998.1661.

Worrall, H., Schweizer, R., Marks, E., Yuan, L., Lloyd, C. and Ramjan, R. (2018), "The effectiveness of support groups: a literature review", Mental Health and Social Inclusion, Vol. 22 No. 2, pp.85-93. DOI: 10.1108/MHSI-12-2017-0055.

Yalom, I. D. (1995), The theory and practice of group psychotherapy (4th ed.). Basic Books, New York. 